\title{
A meta-analysis of the efficacy and safety of accelerated partial breast irradiation versus whole-breast irradiation for early-stage breast cancer
}

\author{
Xiaoyong Xiang ${ }^{1}$, Zhen Ding ${ }^{1}$, Lingling Feng ${ }^{1}$ and Ning $\mathrm{Li}^{1,2^{*}}$
}

\begin{abstract}
Objective: This meta-analysis evaluated the efficacy and safety of accelerated partial breast irradiation versus wholebreast irradiation for early-stage breast cancer after breast-conserving surgery.

Materials and methods: A systematic search of PubMed, Embase, and the Cochrane libraries was performed according to the PRISMA statement the last 10 years to April 7, 2020 to identify the randomized controlled trials of APBI versus WBI for treating patients with early-stage breast cancer. Two independent observers evaluated the identified studies. The obtained data were analyzed using the RevMan 5.3 software.

Results: A total of 10 randomized controlled trials involving 15,500 patients with early-stage breast cancer were selected according to the inclusion and exclusion criteria and included in this meta-analysis. In this meta-analysis, we included ten studies that reported local recurrence and found significant differences in local recurrence rates $(\mathrm{HR}=1.46 ; 95 \% \mathrm{Cl} 1.20-1.79, P=0.0002)$. Further analysis showed that this difference may be related to the choice of treatment methods. No differences in distant metastasis, breast cancer deaths, contralateral breast cancer, diseasefree survival, and overall survival rates were observed between WBI and APBI groups. There was no significant difference in late toxicity, cosmetic outcomes and quality of life between the two groups, the compliance and tolerance of the patients were well. Compared to whole breast irradiation, accelerated partial breast irradiation significantly reduced serious ( $\geq$ grade 2 ) early toxicities, especially regarding acute skin toxicity.
\end{abstract}

Conclusions: The analysis showed that patients receiving APBI had a higher local recurrence rate, but no differences in distant metastasis, breast cancer deaths, contralateral breast cancer, disease-free survival, and overall survival rates.

Keywords: Accelerated partial breast irradiation, Whole-breast irradiation, Breast cancer, Breast-conserving surgery, Meta-analysis

\footnotetext{
*Correspondence: lee_ak@163.com

${ }^{2}$ Department of Radiation Oncology, National Cancer Center/National Clinical Research Center for Cancer/Cancer Hospital, Chinese Academy of Medical Sciences and Peking Union Medical College, Beijing 100021 , China

Full list of author information is available at the end of the article
}

\begin{abstract}
Introduction
Breast cancer was the most frequently diagnosed cancer and the most frequent cause of death from cancer in women [1]. Breast-conserving surgery combined with whole-breast irradiation (WBI) has been the gold standard therapy for patients with early-stage breast cancer, which can yield cancer outcomes comparable to mastectomy $[2,3]$. WBI is usually delivered once per day over several consecutive weeks, making access to effective
\end{abstract} original author(s) and the source, provide a link to the Creative Commons licence, and indicate if changes were made. The images or other third party material in this article are included in the article's Creative Commons licence, unless indicated otherwise in a credit line to the material. If material is not included in the article's Creative Commons licence and your intended use is not permitted by statutory regulation or exceeds the permitted use, you will need to obtain permission directly from the copyright holder. To view a copy of this licence, visit http://creativecommons.org/licenses/by/4.0/. The Creative Commons Public Domain Dedication waiver (http://creativeco mmons.org/publicdomain/zero/1.0/) applies to the data made available in this article, unless otherwise stated in a credit line to the data. 
radiotherapy problematic for women with some socioeconomic barriers [4-6]. As most patients with early-stage breast cancer are cured of their disease, long-term toxicities become more and more critical [2].

Recurrence patterns after breast-conservation surgery suggest that most local recurrences occur predominantly at or near the breast tissue adjacent to the post-excision lumpectomy cavity [7, 8]. Accelerated partial breast irradiation (APBI) only irradiates the tumor bed in one week or less, which is a very favorable treatment that can reduce the burden of care and make it more likely to be accepted by patients [9]. Moreover, due to the smaller irradiation range of APBI, it is expected to reduce toxicity and improve cosmetic effect and quality of life compared with whole-breast irradiation [10].

APBI technology was introduced into clinical practice in the 1990s [11, 12], several different techniques have been developed, including intraoperative irradiation (IORT) with electrons or photons, multicatheter or single brachytherapy, and external beam radiotherapy using intensity-modulated radiotherapy (IMRT) or threedimensional conformal radiotherapy (3DCRT). Current treatment guidelines $[13,14]$ and previous meta-analysis of randomized trials $[15,16]$ regarding APBI mainly address brachytherapy and IORT, these techniques are resource-intensive and invasive, requiring specialized radiotherapy delivery systems and surgical procedures. However, external beam radiotherapy such as 3DCRT and IMRT are noninvasive and only need the widely used CT planning system and linear accelerator. Recently, a large randomized phase 3 trial main using 3DCRT [17] and another [18] using 3DCRT or IMRT in the APBI arm have been officially published, but their results are still controversial. APBI is only applicable to highly selected breast cancer with low-risk factors and has not been widely used in clinical practice.

Here, we performed a systematic review and metaanalysis of all those published randomized studies adopting the APBI for early-stage breast cancer with the primary aims being LR (local recurrence), NR (regional recurrence), safety, cosmetic efficacy, and long-term survival outcome compared with WBI.

\section{Methods}

\section{Literature search strategy}

Before starting the meta-analysis, all the researchers looked at the Prospero, and used the Prisma-P tool to prepare the meta-analysis. A bibliographical search was performed of PubMed, Embase, and the Cochrane Library according to the PRISMA statement the last 10 years to April 7, 2020. The main keywords used for the search were 'breast cancer', 'breast neoplasms', 'accelerated partial breast irradiation, 'APBI,' 'whole breast irradiation', 'WBI'. Searches were limited to human and English language studies. Retrieve the relevant studies manually if necessary.

\section{Selection criteria}

The eligibility criteria of the study are as follows: (1) Patients diagnosed with early-stage breast cancer; (2) Two comparison groups, one group receiving accelerated partial breast radiotherapy and the other group receiving whole breast radiotherapy; (3) At least local recurrence rate data are reported or reported other outcomes (such as OS, DFS, distant metastasis rate, NR, toxicity, cosmetic effect); (4) Randomized controlled trials (RCTs); (5) Language restrictions in English; (6) the sample size of the study was more than 50 cases. Exclusion criteria included the following: (1) Reviews and meta-analyses, abstracts, case reports, and lectures; (2) The clinical diagnosis of patients is unclear; (3) Incorrect or incomplete data that unable to extract data from other relevant studies; (4) Duplicate publications. In the case of overlapping studies, only the most informative or latest researches were included in the analysis. Articles that fulfilled the inclusion and exclusion criteria were retrieved for fulltext evaluation and extracted data from the context of the article.

\section{Data extraction and quality assessment}

After reviewing the full texts of eligible studies, two independent investigators (Xiaoyong Xiang and Zhen Ding) extracted the data and cross-checked all the results. Potential differences in selecting articles and extracting data were resolved with a third reviewer (Ning Li). The extracted variables include general study characteristics (e.g., author, year of publication, study period, median follow-up, number of patients), clinical characteristics (e.g., median age, tumor stage, ER+ or Her-2+ rate, high-grade tumors, histology subtype, pre-menopausal patients rate), treatment characteristics (e.g., radiotherapy technique, RT dosage), short- and long-term outcomes (e.g., local recurrence, regional recurrence, distant metastasis; breast cancer mortality; HR for DFS, OS and LR [if available]; the rate of OS, DFS, LR, NR at 5, 8, 10, and 12 years; cosmetic outcome rating (fair + poor), and toxicities (e.g., Late or acute skin toxicity, fatty necrosis, induration or fibrosis). Because all the included studies are randomized, the methodological quality of the studies was evaluated with the Jadad score. Each study with Jadad scores $\leq 3$ was considered a low-quality study, whereas studies with Jadad scores $>3$ were considered high-quality. The results of the quality assessment are summarized in Table 1. 


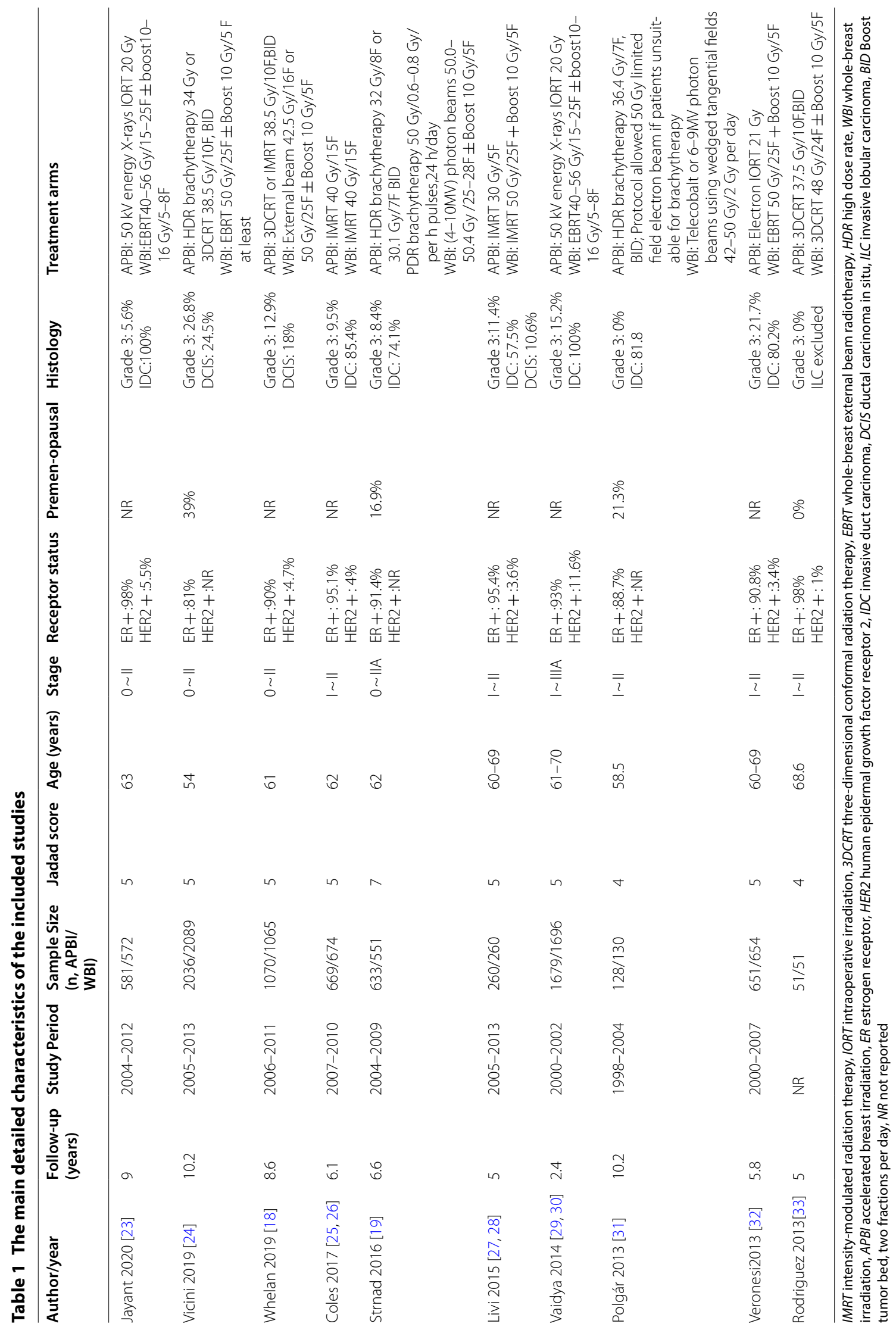




\section{Statistical analysis}

The primary endpoint was the LR percentage in the APBI arm. Secondary endpoints were NR, breast cancer mortality, cosmetic outcome, distant metastasis, OS, DFS, and toxicity. Odds ratio (OR) and $95 \%$ confidence interval $(95 \% \mathrm{CI})$ for count data, HR and 95\% CI for OS and DFS were pooled into formal meta-analyses. Using the Cochrane Q test and the $\mathrm{I}^{2}$ statistics to evaluate the heterogeneity between studies. If heterogeneity was present $\left(P<0.1, \mathrm{I}^{2}>50 \%\right)$, the statistical pooling of effect measures was based on the random-effect model. Otherwise, a fixed-effect model was employ. Subgroup analysis was performed according to radiotherapy techniques (TPS vs. Not TPS). The analysis results were shown in the forest maps, and the potential heterogeneity was identified by sensitivity analysis.

Subsequently, publication bias was assessed using Begg's and Egger's regression asymmetry tests. Statistical analyses were performed using RevMan 5.3 (The Cochrane Centre), and a difference with $\mathrm{P}$ value $<0.05$ was considered statistically significant.

\section{Results}

After screening 692 records, a total of 38 studies were considered to meet the criteria for inclusion in the systematic review potentially. Ultimately, 14 publications reporting on outcomes from 10 studies were included in the analysis. The GEC-ESTRO study reported on efficacy [19], early toxicity and patient compliance [20], late side-effects and cosmetic results [21], and qualityof-life results in different publications [22]. Studies were published in 2013-2020, 15,500 patients with early-stage breast cancer, including 7758 in the APBI group and 7742 in the WBI group. The flowchart of the literature search and selection process is shown in Fig. 1, while the characteristics of the eligible studies and main outcomes are summarized in Tables 1 and 2.

\section{Local recurrence}

Ten eligible studies had local recurrence data, and the studies included 7,758 patients in the APBI group and 7,742 patients in the WBI group. There was a significant difference between the two groups $(\mathrm{HR}=1.46,95 \% \mathrm{CI}$ $1.20-1.79, P=0.0002$; heterogeneity $P=0.14, \mathrm{I}^{2}=33 \%$, Fig. 2). The analysis showed that patients receiving APBI had a higher local recurrence rate.

\section{Regional recurrence}

Five studies can extract HR data of regional recurrence. Meta-analysis showed that there was no statistical significance between the two groups, but the WBI group had a trend to reduce the regional recurrence risk $(\mathrm{HR}=1.84$; 95\% CI 0.94-3.63, $P=0.08$, Fig. 3). The included studies had no significant heterogeneity $\left(P=0.59, \mathrm{I}^{2}=0 \%\right)$.

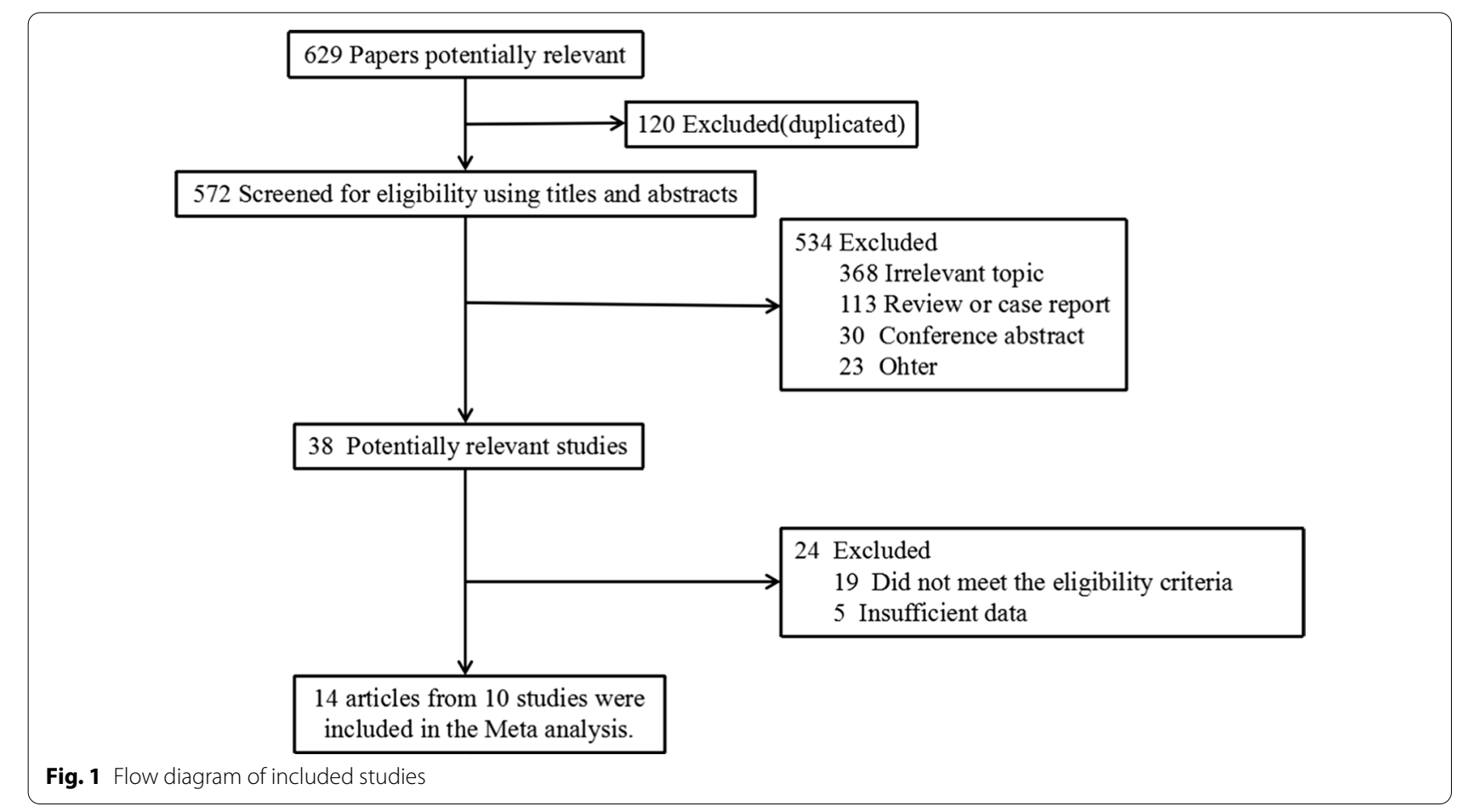


Table 2 Main long-term outcomes

\begin{tabular}{|c|c|c|c|c|c|c|c|c|c|}
\hline Author/year & Group & $\begin{array}{l}5-8-10- \\
12 \text { year DFS }\end{array}$ & $\begin{array}{l}5-8-10-12 \text { year } \\
\text { OS }\end{array}$ & $\begin{array}{l}5-8-10- \\
12 \text { year } \\
\text { LR }\end{array}$ & $\begin{array}{l}\text { 5-8-10 year } \\
\text { NR }\end{array}$ & $\begin{array}{l}\text { Breast } \\
\text { cancer } \\
\text { deaths }\end{array}$ & $\begin{array}{l}\text { Distant } \\
\text { metastasis }\end{array}$ & $\begin{array}{l}\text { Contralateral } \\
\text { breast cancer }\end{array}$ & $\begin{array}{l}\text { Second } \\
\text { primary } \\
\text { cancers }\end{array}$ \\
\hline $\begin{array}{l}\text { Jayant } 2020 \\
\text { [23] }\end{array}$ & $\begin{array}{l}\text { APBI } \\
\text { WBI }\end{array}$ & NR & $\begin{array}{l}96.70 \% /- \\
\quad / 88.62 \% / 83.13 \% \\
97.69 \% /- \\
\quad / 87.77 \% / 84.72 \%\end{array}$ & $\begin{array}{l}3.96 \% /- \\
/ 7.2 \% / 7.2 \% \\
1.05 \% /- \\
/ 2.8 \% / 3.5 \%\end{array}$ & NR & $\begin{array}{l}3.61 \% \\
3.0 \%\end{array}$ & $\begin{array}{l}1.0 \% \\
1.4 \%\end{array}$ & $N R$ & NR \\
\hline $\begin{array}{l}\text { Vicini } 2019 \\
\quad[24]\end{array}$ & $\begin{array}{l}\text { APBI } \\
\text { WBI }\end{array}$ & $\begin{array}{l}-/-/ 78.1 \% /- \\
-/-/ 79.7 \% /-\end{array}$ & $\begin{array}{l}-/-/ 90.6 \% /- \\
-/-/ 91.3 \% /-\end{array}$ & $\begin{array}{l}-/-/ 4.6 \% /- \\
-/-/ 3.9 \% /-\end{array}$ & NR & $\begin{array}{l}2.3 \% \\
2.2 \%\end{array}$ & $\begin{array}{l}2.4 \% \\
3.1 \%\end{array}$ & $\begin{array}{l}3.0 \% \\
3.5 \%\end{array}$ & $\begin{array}{l}9 \% \\
10 \%\end{array}$ \\
\hline $\begin{array}{l}\text { Whelan } 2019 \\
\text { [18] }\end{array}$ & $\begin{array}{l}\text { APBI } \\
\text { WBI }\end{array}$ & $\begin{array}{l}96.4 \% / 94.9 \% /-/ \\
96.8 \% / 95.4 \% /-/\end{array}$ & $\begin{array}{l}96.2 \% / 93.6 \% /-/- \\
97 \% / 94.3 \% /-/-\end{array}$ & $\begin{array}{l}2.3 \% / 3 \% /-/- \\
1.7 \% / 2.8 \% /- \\
\quad /-\end{array}$ & $\begin{array}{l}-/ 0.4 \% /- \\
-/ 0.2 \% /-\end{array}$ & $\begin{array}{l}1.7 \% \\
1.5 \%\end{array}$ & $\begin{array}{l}1.9 \% \\
1.7 \%\end{array}$ & $\begin{array}{l}2.7 \% \\
3.6 \%\end{array}$ & $\begin{array}{l}10.6 \% \\
9.0 \%\end{array}$ \\
\hline $\begin{array}{c}\text { Coles } 2017 \\
{[25,26]}\end{array}$ & $\begin{array}{l}\text { APBI } \\
\text { WBI }\end{array}$ & NR & NR & $\begin{array}{l}0.5 \% /-/-/- \\
1.1 \% /-/-/-\end{array}$ & $\begin{array}{l}0.3 \% /-/- \\
0.1 \% /-/-\end{array}$ & $\begin{array}{l}1.5 \% \\
1.3 \%\end{array}$ & $\begin{array}{l}1.8 \% \\
1.9 \%\end{array}$ & $\begin{array}{l}1.9 \% \\
1.8 \%\end{array}$ & $\begin{array}{l}5.5 \% \\
7.0 \%\end{array}$ \\
\hline $\begin{array}{l}\text { Strnad } 2016 \\
{[19-22]}\end{array}$ & $\begin{array}{l}\text { APBI } \\
\text { WBI }\end{array}$ & $\begin{array}{l}95.03 \% /-/-/- \\
94.45 \% /-/-/-\end{array}$ & $\begin{array}{l}97.27 \% /-/-/- \\
95.55 \% /-/-/-\end{array}$ & $\begin{array}{l}1.44 \% /-/-/- \\
0.92 \% /-/-/-\end{array}$ & $\begin{array}{l}0.47 \% /-/- \\
0.18 \% /-/-\end{array}$ & $\begin{array}{l}0.6 \% \\
0.7 \%\end{array}$ & $\begin{array}{l}0.8 \% \\
0.9 \%\end{array}$ & $\begin{array}{l}0.8 \% \\
0.9 \%\end{array}$ & $\begin{array}{l}5.5 \% \\
4.0 \%\end{array}$ \\
\hline $\begin{array}{l}\text { Livi } 2015 \text { [27, } \\
\quad 28]\end{array}$ & $\begin{array}{l}\text { APBI } \\
\text { WBI }\end{array}$ & $N R$ & $\begin{array}{l}99.4 \% /-/-/- \\
96.6 \% /-/-/-\end{array}$ & $\begin{array}{l}1.5 \% /-/-/- \\
1.4 \% /-/-/-\end{array}$ & $\begin{array}{l}1.5 \% /-/- \\
1.9 \% /-/-\end{array}$ & $\begin{array}{l}0.4 \% \\
1.2 \%\end{array}$ & $\begin{array}{l}1.2 \% \\
1.5 \%\end{array}$ & $\begin{array}{l}1.2 \% \\
2.7 \%\end{array}$ & NR \\
\hline $\begin{array}{c}\text { Vaidya } 2014 \\
{[29,30]}\end{array}$ & $\begin{array}{l}\text { APBI } \\
\text { WBI }\end{array}$ & NR & $\mathrm{NR}$ & $\begin{array}{l}3.3 \% /-/-/- \\
1.3 \% /-/-/-\end{array}$ & $\begin{array}{l}0.5 \% /-/- \\
0.3 \% /-/-\end{array}$ & $\begin{array}{l}1.2 \% \\
0.9 \%\end{array}$ & $\begin{array}{l}0.5 \% \\
0.4 \%\end{array}$ & $N R$ & NR \\
\hline $\begin{array}{l}\text { Polgár } 2013 \\
\text { [31] }\end{array}$ & $\begin{array}{l}\text { APBI } \\
\text { WBI }\end{array}$ & $\begin{array}{c}88.8 \% /- \\
/ 85.3 \% /- \\
90.5 \% /- \\
/ 83.6 \% /-\end{array}$ & $\begin{array}{l}-/-/ 79.7 \% /- \\
-/-/ 82.1 \% /-\end{array}$ & $\begin{array}{l}4.0 \% /- \\
\quad / 5.9 \% /- \\
3.3 \% /- \\
\quad / 5.1 \% /-\end{array}$ & $\begin{array}{l}1.6 \% /-/ 2.5 \% \\
1.7 \% /-/ 1.7 \%\end{array}$ & $N R$ & $\begin{array}{l}5.5 \% \\
8.5 \%\end{array}$ & $\begin{array}{l}7.0 \% \\
6.2 \%\end{array}$ & $\begin{array}{l}12.5 \% \\
10.8 \%\end{array}$ \\
\hline $\begin{array}{l}\text { Veronesi2013 } \\
\text { [32] }\end{array}$ & $\begin{array}{l}\text { APBI } \\
\text { WBI }\end{array}$ & NR & $\begin{array}{l}96.8 \% /-/-/- \\
96.9 \% /-/-/-\end{array}$ & $\begin{array}{l}4.4 \% /-/-/- \\
0.4 \% /-/-/-\end{array}$ & $\begin{array}{l}1.0 \% /-/- \\
0.3 \% /-/-\end{array}$ & $\begin{array}{l}3.5 \% \\
3.1 \%\end{array}$ & $\begin{array}{l}5.1 \% \\
5.4 \%\end{array}$ & $\begin{array}{l}1.2 \% \\
2.0 \%\end{array}$ & $\begin{array}{l}4.3 \% \\
5.4 \%\end{array}$ \\
\hline $\begin{array}{l}\text { Rodriguez } \\
2013 \text { [33] }\end{array}$ & $\begin{array}{l}\text { APBI } \\
\text { WBI }\end{array}$ & NR & NR & $\begin{array}{l}0 \% /-/-/- \\
0 \% /-/-/-\end{array}$ & $\begin{array}{l}0 \% /-/- \\
0 \% /-/-\end{array}$ & $\begin{array}{l}0 \% \\
0 \%\end{array}$ & $\begin{array}{l}0 \% \\
0 \%\end{array}$ & $N R$ & $\begin{array}{l}5.5 \% \\
7.0 \%\end{array}$ \\
\hline
\end{tabular}

OS overall survival, DFS disease-free survival, $L R$ local recurrence, $R R$ regional recurrence, $N R$ no reported, Adverse cosmesis physician-scored cosmetic results fair and poor, Second primary cancers had a second primary tumor in the contralateral-breast or a second tumor at a site other than the breast

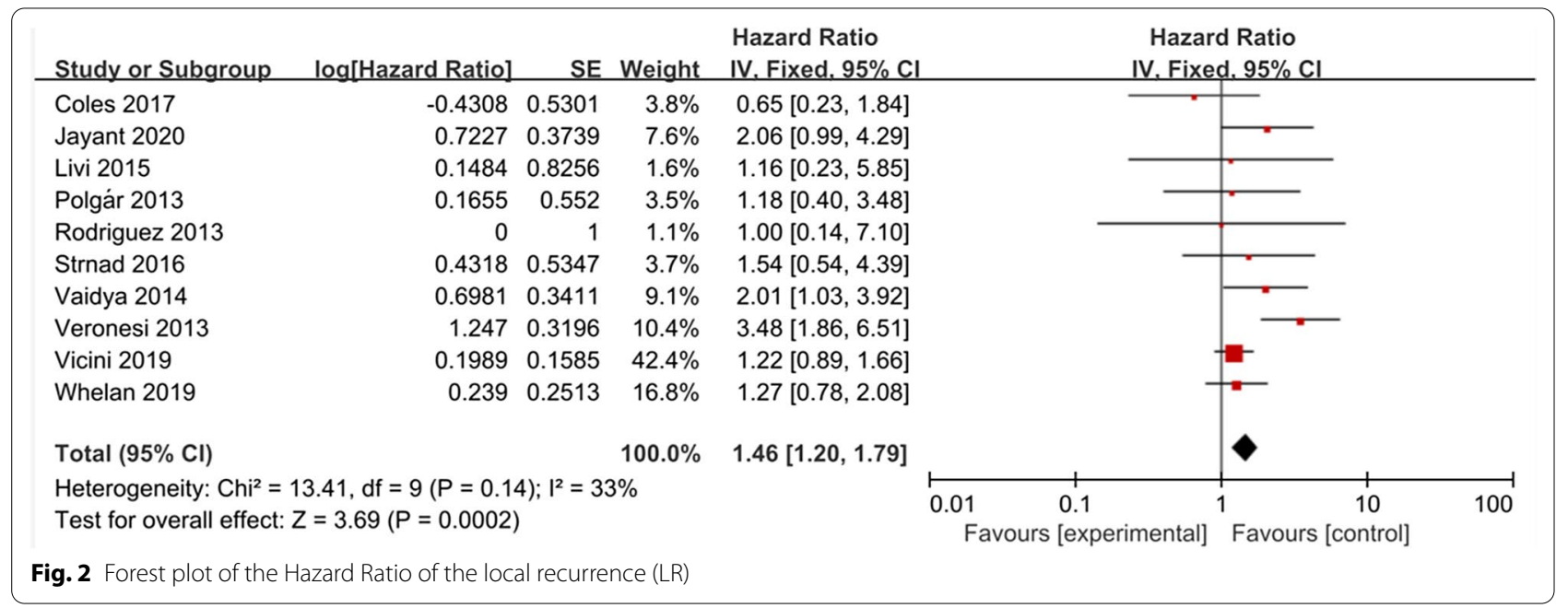

\section{Distant metastasis}

Ten studies reported the impact of APBI/WBI on distant metastasis.The meta-analysis showed that there was no significant difference between APBI group and WBI group $(\mathrm{HR}=1.17$; 95\% CI 0.96-1.43, $P=0.11$; heterogeneity $P=1.00, \mathrm{I}^{2}=0 \%$, Fig. 4 ).

\section{Overall survival}

Nine studies, including 15,242 patients, compared the OS rate of APBI versus WBI in patients with earlystage breast cancer. The heterogeneity test results were $P=0.50$ and $\mathrm{I}^{2}=0 \%$, indicating a low risk of heterogeneity; the fixed-effects model was then used. The forest 
plots of the meta-analysis showed that there was no significant difference in overall survival rate between the APBI group and WBI group $(\mathrm{HR}=1.11$, 95\% CI $0.98-$ $1.27, P=0.09$; heterogeneity $P=0.50, \mathrm{I}^{2}=0 \%$, Fig. 5 ).

\section{Disease-free survival}

There were five eligible studies had regional recurrence data; these studies included 4536 patients in the APBI group and 4509 patients in the WBI group. Subsequent analysis of these studies revealed that there was

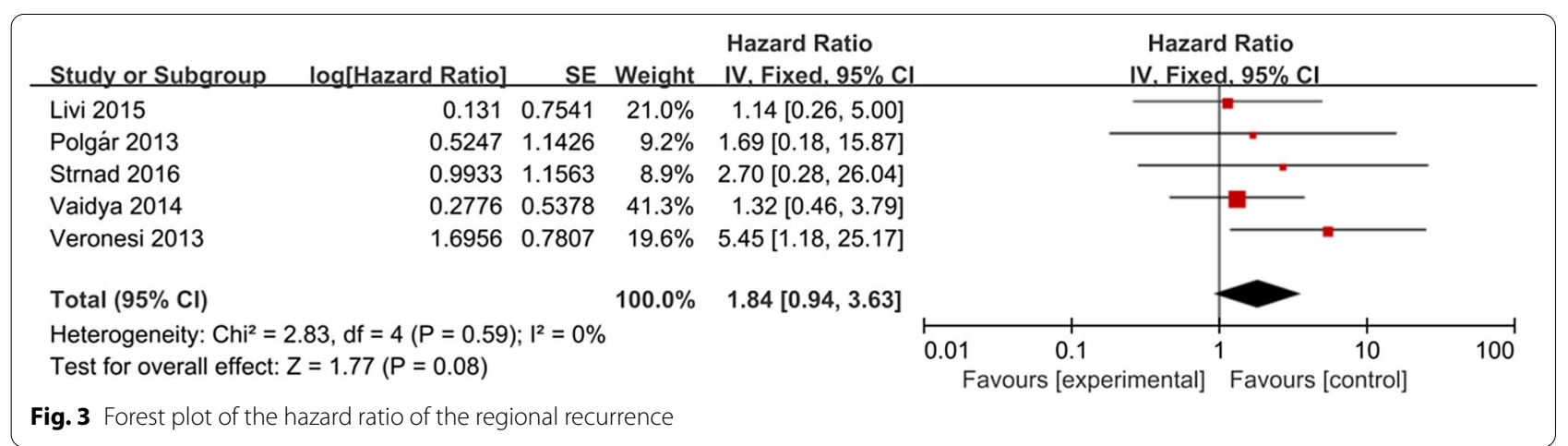

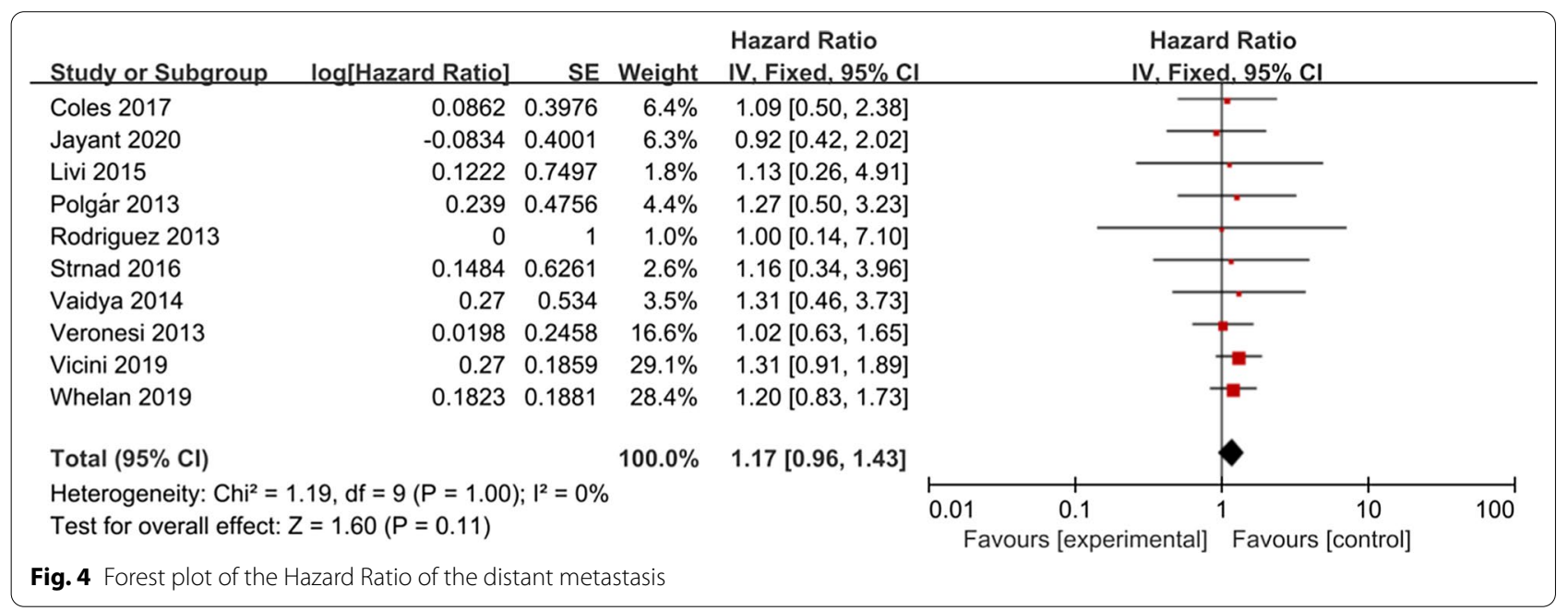

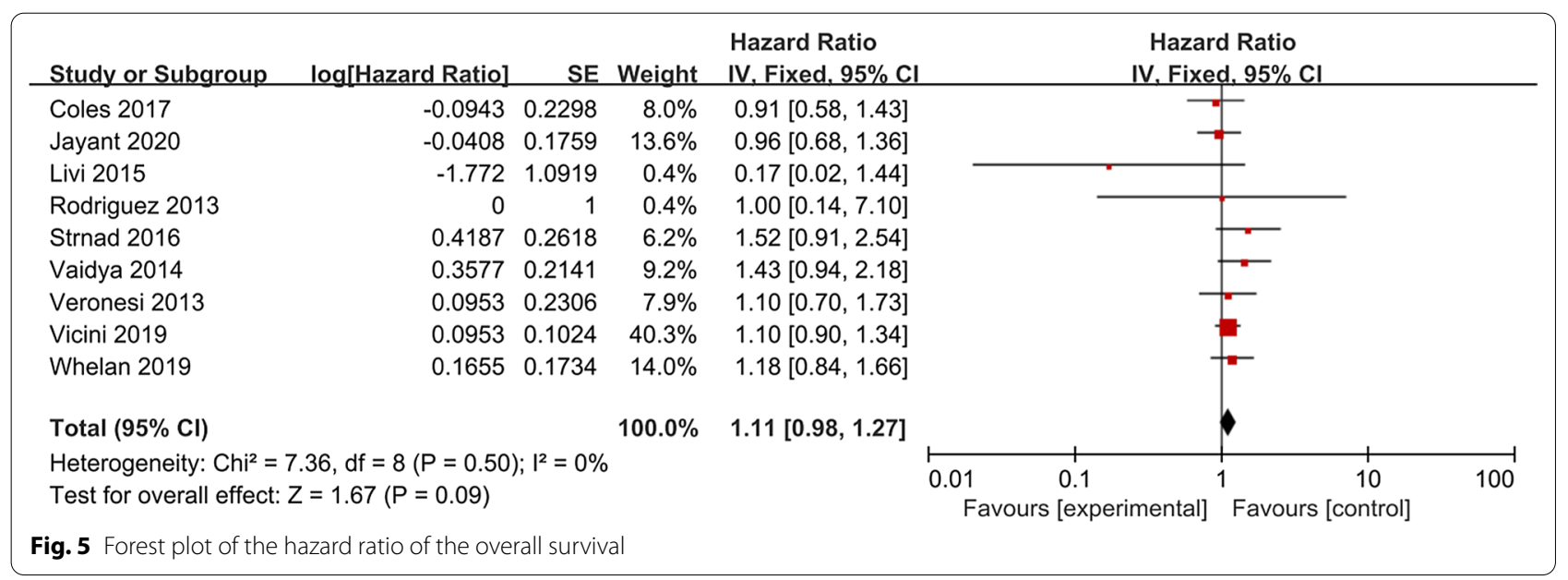


no significant difference in disease-free survival rate between APBI and WBI groups (HR $=1.11,95 \%$ CI 0.99 $1.24, P=0.09$, Fig. 6 ). The included studies had no significant heterogeneity $\left(P=0.93, \mathrm{I}^{2}=0 \%\right)$.

\section{Breast cancer deaths}

Breast cancer death was reported for nine studies; there were 7729 patients in the APBI group and 7596 patients in the WBI group. Subsequent analysis of these studies revealed no significant difference in breast cancer mortality between two groups $(\mathrm{OR}=1.12,95 \% \mathrm{CI} 0.88-1.42$, $P=0.36$, Fig. 7). The included studies had no significant heterogeneity $\left(P=0.98, \mathrm{I}^{2}=0 \%\right)$.

\section{Contralateral breast cancer}

Seven studies were available for comparative analysis of contralateral breast cancer, including 5,500 patients in the APBI group, and 5,370 patients in the WBI group. Meta-analysis showed that there was no significant difference in the rate of contralateral breast cancer between the two groups $(\mathrm{OR}=0.82,95 \% \mathrm{CI} 0.46-1.23, P=0.10$, Fig. 8) and no heterogeneity between the included studies $\left(P=0.87, \mathrm{I}^{2}=0 \%\right)$.

\section{Toxicity, cosmetic outcomes and quality of life}

Eight, five, and two studies respectively reported the major toxicity, cosmetic effects, and quality of life. Because their endpoints and criteria were not uniform, we presented a descriptive analysis of their results (Table 3). In addition, a sub-study of the TARGIT-A trial found that patients treated with APBI have similar self-reported cosmetic outcome but better breastrelated quality of life outcomes than patients treated with WBI [46], and it is found that for cosmetic appearance and other results, the patient's point of view is the most important [47].

\section{Publication bias}

There was no significant publication bias in the metaanalysis of all effects. For the local recurrence metaanalysis, there was no evidence of publication bias, and neither Begg nor Egger test was significant $(P=0.59$ and 0.25).

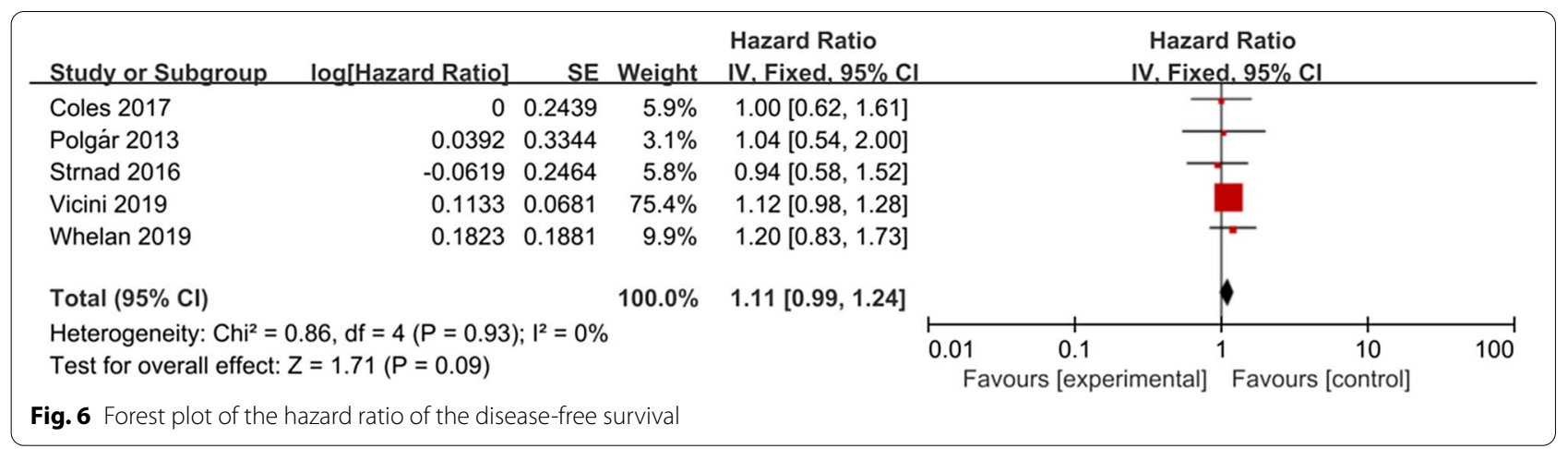

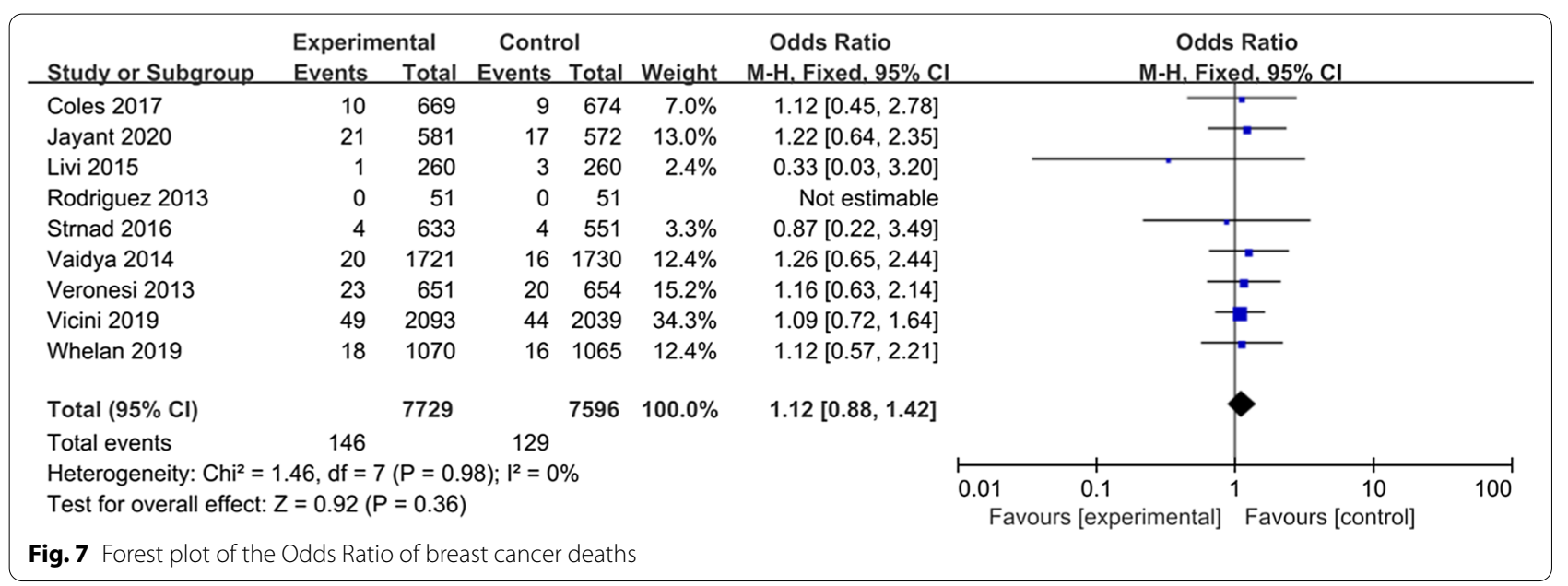




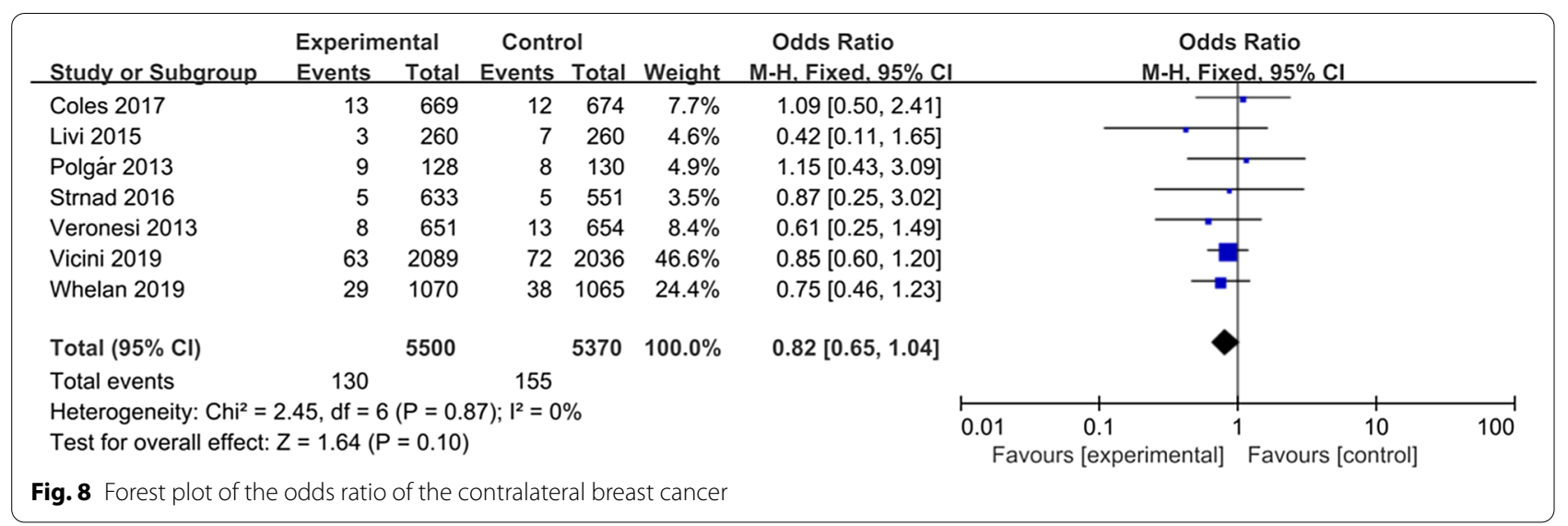

\section{Discussion}

Adjuvant whole-breast irradiation after breast-conserving surgery can significantly reduce the risk of local and regional recurrences and has shown a positive influence on overall survival especially for patients with an intermediate to high absolute risk for local recurrences compared to lumpectomy alone, which has become the standard treatment for early-stage breast cancer [3, 34, 35]. Although adjuvant radiotherapy after breastconserving surgery is crucial, many studies have shown that local recurrences frequently occur near the primary tumor location. Consequently, it is considered that radiotherapy's main benefits arise from irradiating partial breast around the surgical cavity [7, 36, 37].

Accelerated partial breast irradiation is performed by aiming radiation delivery to the surgical cavity and its surrounding 1-2 $\mathrm{cm}$ breast tissue, which is considered to be the tissue with the highest risk of tumor cell residue after breast-conserving surgery $[17,18]$. There are numerous techniques for APBI, including external beambased APBI; IORT with either gamma-rays, photons or electrons; brachytherapy (interstitial or intracavitary) [38]. Commonly fractionation schemes include $38 \mathrm{~Gy}$ in 10 fractions with external beam-based APBI, 20-21 Gy in one fraction with IORT, or 34 Gy in 10 fractions for brachytherapy [38-40]. Because the irradiation range is narrowed and the $\alpha / \beta$ ratio of breast cancer cells is lower than that of other tumors [41], accelerated large-division irradiation does not significantly increase acute or late radiotherapy responses. At the same time, APBI shortens the total treatment time, saves medical resources, and reducing patients' treatment costs and waiting time, which is of great economic significance $[9,42]$.

Although APBI has many advantages, there is still no unified standard for its techniques, indications, and fractionation schemes. At present, several societies have published guidelines to define whether patients can perform APBI: those of ASTRO (American Society for Radiation Oncology), GECESTRO (European Society for Radiotherapy and Oncology), and ABS (American Brachytherapy Society)[13, 43, 44]. In addition to consistent standards regarding age $\geq 50$ years, negative node status, and absence of lymphovascular space invasion. There is no general consensus on other criteria such as tumor size, molecular typing, lymph node invasion, and other characteristics $[13,43,44]$. Consequently, the current guidelines recommend that patients receiving $\mathrm{APBI}$ should be carefully selected according to their clinical characteristics.

We reviewed a previously published meta-analysis that included seven trials for a total of 7452 patients [16]. This meta-analysis includes a study published in 1993 on the use of single-electron beams for APBI irradiation [11]. We believe that the technical conditions of radiotherapy used at that time are significantly different from those used later, so we have only included the latest ten studies. This meta-analysis showed that there was a significant difference in the 5-year local recurrence rate between the two groups $(\mathrm{HR}=4.5$, 95\% CI 1.78-11.61, $P=0.002$ ). There was no significant difference in regional recurrence, systemic recurrence, overall survival, or mortality rates between the two groups. The two groups' side effects and cosmetic effects were similar, but intraoperative radiotherapy seemed to have greater acute side effects [16].

A recent meta-analysis, the literature search that ended in January 2018, included a total of eleven publications reporting nine studies findings, but two of them were informal data from conference summaries [45]. Our study includes accurate data that have been officially published in both studies, as well as additional research on long-term follow-up survival data for intraoperative radiotherapy. This study used odds ratios (OR) in their metaanalysis of local recurrence, non-breast cancer mortality, 


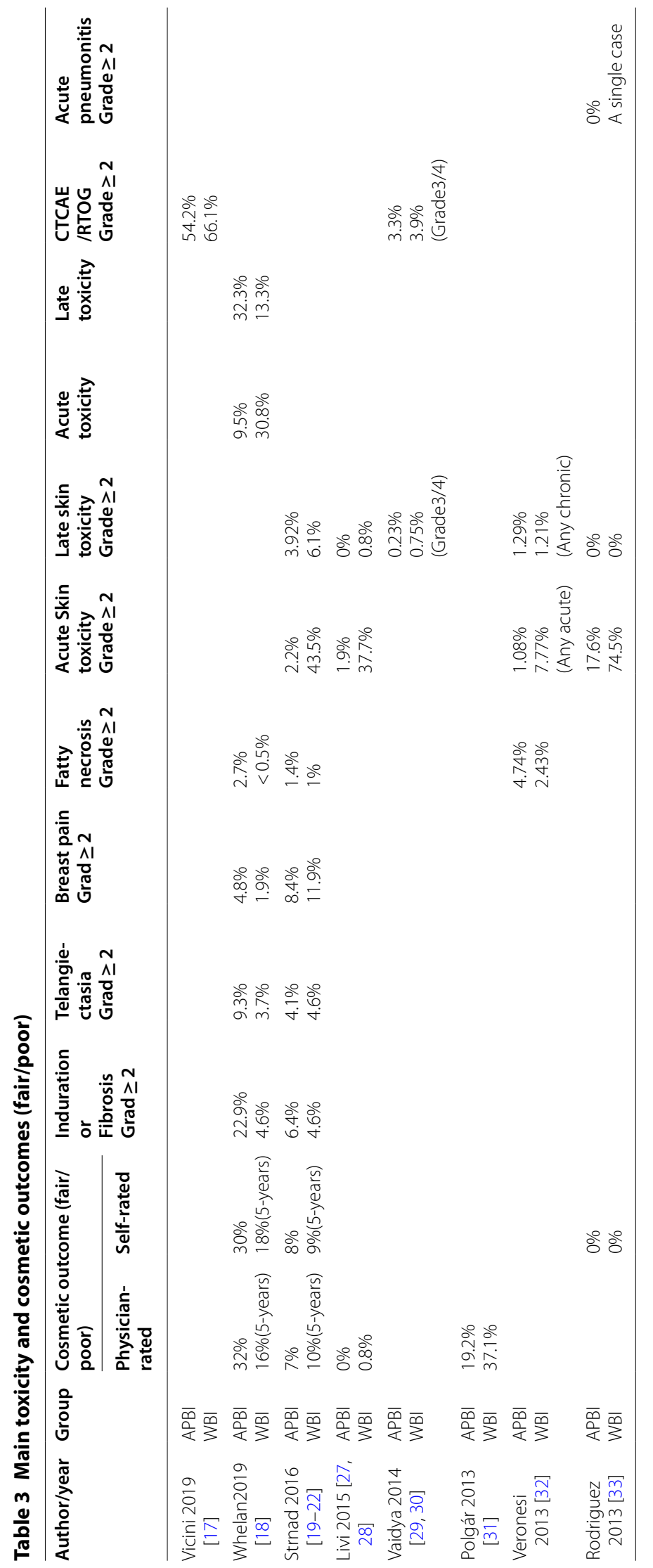


overall survival, regional recurrence, contralateral breast cancer, disease-free survival rate, and toxicity. However, $\mathrm{HR}$ is the appropriate natural indicator of time-to-event data, and we believe that HR is more accurate than OR in survival analysis. Consequently, HR is extracted as much as possible in our study, and then meta-analysis is performed. Besides, this study performed a subgroup analysis according to radiotherapy techniques, such as EBRT (external beam radiation treatment), brachytherapy, IORT, and other techniques. The subgroup analysis may not be the most appropriate because of each subgroup, including only a small number of studies. However, we performed a subgroup analysis of local recurrence according to whether the patients received therapy with Radiotherapy Treatment Planning System (TPS). There were seven studies in the TPS group and three studies in the Not TPS group.

In this meta-analysis, we included ten studies that reported local recurrence and found significant differences in local recurrence rates $(\mathrm{HR}=1.46$; $95 \% \mathrm{CI} 1.20$ 1.79, $P=0.0002$; heterogeneity $P=0.14, \mathrm{I}^{2}=33 \%$ ). We also note that there is a slight heterogeneity between the included studies, which may be due to the choice of treatment techniques. A total of three studies used IORT, two of which used IOERT (Intraoperative Electron Radiation Therapy)[32], and the other used TARGIT (Targeted intra-operative radiotherapy) [23, 29]. Obviously, 3DCRT, IMRT or brachytherapy based on TPS system have an accurate definition of the target area or dose distribution, while IORT and TARGIT are not involved. Therefore, we performed a subgroup analysis according to whether the patients received therapy with Radiotherapy Treatment Planning System (TPS). The results showed that the studies of the subgroups were homogeneous $\left(P>0.1, \mathrm{I}^{2}=0 \%\right)$. Compared with the total heterogeneity, the heterogeneity of the subgroups was significantly reduced after subgroup analysis, and there was a statistical difference between the subgroups $\left(P=0.002, \mathrm{I}^{2}=90.0 \%\right)$, it is suggested that the main cause of heterogeneity could be the TPS technology. Subset analyses showed that without TPS, APBI could significantly increase LR rate $(\mathrm{HR}=2.50,95 \% \mathrm{CI}$ 1.69-3.68, $P<0.00001$; heterogeneity $P=0.42, \mathrm{I}^{2}=0 \%$ ). However, with TPS, there was no significant difference in LR between the APBI group and the WBI group $(\mathrm{HR}=1.20,95 \% \mathrm{CI} 0.95-1.52, P=0.13$; heterogeneity $\left.P=0.95, \mathrm{I}^{2}=0 \%\right)$. Therefore, we made a assumption that although APBI showed significant disadvantages in local control (similar to the results of previous meta-analyses), the selection of appropriate radiotherapy techniques may eliminate this difference. Although, from the patient's perspective, perhaps the most convenient APBI technique is IORT, which requires only one irradiation during breast-conserving surgery. IORT can not only improve the treatment compliance of patients but also decrease the irradiation of healthy organs and reduce the cost of treatment. However, external beam-based APBI, such as 3DCRT, IMRT radiotherapy are widely available. Multiple randomized trials using this radiation technique have been published and achieved the desired results. Another TPS-based brachytherapy technique predominantly depends on the experience and skills of the treating physician and is only available inexperienced institutions. Consequently, perhaps external beam-based APBI is the most appropriate technology.

No differences in distant metastasis, breast cancer deaths, contralateral breast cancer, disease-free survival, and overall survival rates were observed between WBI and APBI groups. In other words, our study has shown that when using APBI, these outcomes are not worse than WBI. Five studies can extract HR data of regional recurrence, the meta-analysis showed that there was no statistical significance between the two groups, but the WBI group had a trend to reduce the regional recurrence risk $(\mathrm{HR}=1.84 ; 95 \% \mathrm{CI} 0.94-3.63 ; P=0.08)$.

Because the endpoints and criteria of toxicity, cosmetic outcomes, and quality of life were not uniform, we only made a descriptive analysis of their results. Compared to WBI, APBI significantly reduced serious ( $\geq$ grade 2 ) early toxicities, especially regarding acute skin toxicity $[18,20$, $28,32,33]$. Although less acute toxicity was observed, the regimen used was associated with an increase in late normal-tissue toxicity and adverse cosmesis in the RAPID trial, which might be related to the twice per day treatment [18]. Two studies reported patients' quality-of-life results; APBI was not associated with worse quality of life than WBI $[22,27]$. Overall, there was no significant difference in toxicity, cosmetic outcomes and quality of life between the two groups, the compliance and tolerance of the patients were well.

The main limitations of our meta-analysis are related to the included studies rather than the systematic review itself. Because there are significant differences in times and treatment methods for APBI and WBI, blinding of patients and/or outcome assessors was not possible. However, it should be considered that in this kind of intervention, masking is not possible. In addition, most studies do not have independent data analysts. We believe that the objective results are unlikely to be significantly influenced by the lack of investigator-blind and independent data analysts.

\section{Conclusion}

In conclusion, among patients who had received breastconserving treatment for early-stage breast cancer, the rate of local recurrence was significantly higher for APBI than for WBI, but no differences in distant metastasis, 
breast cancer deaths, contralateral breast cancer, diseasefree survival, and overall survival rates. Based on our preliminary investigation of radiotherapy techniques, we recommend that external beam-based APBI should be considered in the treatment choice for selected low-risk patients, that brachytherapy is only available in experienced institutions and intraoperative radiotherapy should be used with caution.

\begin{abstract}
Abbreviations
IMRT: Intensity-modulated radiation therapy; IORT: Intraoperative irradiation; 3DCRT: Three-dimensional conformal radiation therapy; EBRT: Whole-breast external beam radiotherapy; HDR: High dose rate; WBI: Whole-breast irradiation; APBI: Accelerated breast irradiation; ER: Estrogen receptor; HER2: Human epidermal growth factor receptor 2; IDC: Invasive duct carcinoma; DCIS: Ductal carcinoma in situ; ILC: Invasive lobular carcinoma; BID: Boost tumor bed, two fractions per day; NR: Not reported; OS: Overall survival; DFS: Disease-free survival; LR: Local recurrence; RR: Regional recurrence; NR: No reported; Adverse cosmesis: Physician-scored cosmetic results fair and poor; Second primary cancers: Had a second primary tumor in the contralateral-breast or a second tumor at a site other than the breast; SE: Standard error.
\end{abstract}

\section{Acknowledgements}

Not applicable.

\section{Authors' contributions}

XX conceived and coordinated the study, designed, performed, and analyzed the experiments, and wrote the manuscript. ZD and LF collected and analyzed the data. NL revised the manuscript. All authors read and approved the final manuscript.

\section{Funding}

Not applicable.

\section{Availability of data and materials}

All data generated or analyzed during this study are included in this manuscript.

\section{Ethics approval and consent to participate}

All analyses were based on previously published studies, and hence no ethical approval and patient consent were required.

\section{Consent for publication}

Not applicable.

\section{Competing interests}

The authors declare that they have no competing interests.

\section{Author details}

${ }^{1}$ Department of Radiation Oncology, National Cancer Center/National Clinical Research Center for Cancer/Cancer Hospital \& Shenzhen Hospital, Chinese Academy of Medical Sciences and Peking Union Medical College, Shenzhen 518116, China. ${ }^{2}$ Department of Radiation Oncology, National Cancer Center/National Clinical Research Center for Cancer/Cancer Hospital, Chinese Academy of Medical Sciences and Peking Union Medical College, Beijing 100021, China.

Received: 11 August 2020 Accepted: 28 January 2021

Published online: 02 February 2021

\section{References}

1. Ferlay J, et al. Estimating the global cancer incidence and mortality in 2018: GLOBOCAN sources and methods. Int J Cancer. 2019;144(8):1941-53.
2. Darby $S$, et al. Effect of radiotherapy after breast-conserving surgery on 10-year recurrence and 15-year breast cancer death: meta-analysis of individual patient data for 10,801 women in 17 randomised trials. Lancet. 2011;378(9804):1707-16.

3. Clarke $M$, et al. Effects of radiotherapy and of differences in the extent of surgery for early breast cancer on local recurrence and 15-year survival: an overview of the randomised trials. Lancet. 2005;366(9503):2087-106.

4. Lam J, et al. Examining determinants of radiotherapy access: do cost and radiotherapy inconvenience affect uptake of breast-conserving treatment for early breast cancer? Clin Oncol (R Coll Radiol). 2015;27(8):465-71.

5. Parekh A, et al. Impact of race, ethnicity, and socioeconomic factors on receipt of radiation after breast conservation surgery: analysis of the national cancer database. Breast Cancer Res Treat. 2018;172(1):201-8.

6. Haviland JS, et al. The UK Standardisation of Breast Radiotherapy (START) trials of radiotherapy hypofractionation for treatment of early breast cancer: 10-year follow-up results of two randomised controlled trials. Lancet Oncol. 2013;14(11):1086-94.

7. Veronesi $U$, et al. Radiotherapy after breast-conserving surgery in small breast carcinoma: long-term results of a randomized trial. Ann Oncol. 2001;12(7):997-1003.

8. Liljegren $\mathrm{G}$, et al. 10-Year results after sector resection with or without postoperative radiotherapy for stage I breast cancer: a randomized trial. J Clin Oncol. 1999;17(8):2326-33.

9. Smith $\mathrm{BD}$, et al. Accelerated partial breast irradiation consensus statement from the American Society for Radiation Oncology (ASTRO). Int J Radiat Oncol Biol Phys. 2009;74(4):987-1001.

10. Mouw KW, Harris JR. Irradiation in early-stage breast cancer: conventional whole-breast, accelerated partial-breast, and accelerated whole-breast strategies compared. Oncology (Williston Park). 2012;26(9):820-30.

11. Ribeiro GG, et al. The Christie Hospital breast conservation trial: an update at 8 years from inception. Clin Oncol (R Coll Radiol). 1993;5(5):278-83.

12. Ribeiro $G G$, et al. Conservation of the breast using two different radiotherapy techniques: interim report of a clinical trial. Clin Oncol (R Coll Radiol). 1990;2(1):27-34.

13. Correa $C$, et al. Accelerated partial breast irradiation: executive summary for the update of an ASTRO evidence-based consensus statement. Pract Radiat Oncol. 2017;7(2):73-9.

14. Polgár C, et al. Patient selection for accelerated partial-breast irradiation (APBI) after breast-conserving surgery: recommendations of the Groupe Européen de Curiethérapie-European Society for Therapeutic Radiology and Oncology (GEC-ESTRO) breast cancer working group based on clinical evidence (2009). Radiother Oncol. 2010;94(3):264-73.

15. Marta GN, et al. Accelerated partial irradiation for breast cancer: Systematic review and meta-analysis of 8653 women in eight randomized trials. Radiother Oncol. 2015;114(1):42-9.

16. Liu G, et al. Efficacy and safety of accelerated partial breast irradiation: a meta-analysis of published randomized studies. Oncotarget. 2017;8(35):59581.

17. Vicini FA, et al. Long-term primary results of accelerated partial breast irradiation after breast-conserving surgery for early-stage breast cancer: a randomised, phase 3, equivalence trial. The Lancet. 2019:394(10215):2155-64.

18. Whelan TJ, et al. External beam accelerated partial breast irradiation versus whole breast irradiation after breast conserving surgery in women with ductal carcinoma in situ and node-negative breast cancer (RAPID): a randomised controlled trial. The Lancet. 2019;394(10215):2165-72.

19. Strnad VP, et al. 5-year results of accelerated partial breast irradiation using sole interstitial multicatheter brachytherapy versus whole-breast irradiation with boost after breast-conserving surgery for low-risk invasive and in-situ carcinoma of the female breast: a randomised, phase 3, noninferiority trial. The Lancet. 2016;387(10015):229-38.

20. Ott OJ, et al. GEC-ESTRO multicenter phase 3-trial: accelerated partial breast irradiation with interstitial multicatheter brachytherapy versus external beam whole breast irradiation: Early toxicity and patient compliance. Radiother Oncol. 2016;120(1):119-23.

21. Polgár $C$, et al. Late side-effects and cosmetic results of accelerated partial breast irradiation with interstitial brachytherapy versus wholebreast irradiation after breast-conserving surgery for low-risk invasive and in-situ carcinoma of the female breast: 5-year results of a randomised, controlled, phase 3 trial. Lancet Oncol. 2017;18(2):259-68. 
22. Schäfer R, et al. Quality-of-life results for accelerated partial breast irradiation with interstitial brachytherapy versus whole-breast irradiation in early breast cancer after breast-conserving surgery (GEC-ESTRO): 5-year results of a randomised, phase 3 trial. Lancet Oncol. 2018;19(6):834-44.

23. Vaidya JS, et al. Effect of delayed targeted intraoperative radiotherapy vs whole-breast radiotherapy on local recurrence and survival. JAMA Oncol. 2020;6:e200249.

24. Vicini FA, et al. Long-term primary results of accelerated partial breast irradiation after breast-conserving surgery for early-stage breast cancer: a randomised, phase 3, equivalence trial. Lancet. 2019;394(10215):2155-64.

25. Coles $C E$, et al. Partial-breast radiotherapy after breast conservation surgery for patients with early breast cancer (UK IMPORT LOW trial): 5-year results from a multicentre, randomised, controlled, phase 3, noninferiority trial. The Lancet. 2017;390(10099):1048-60.

26. Bhattacharya IS, et al. Can patient-reported outcomes be used instead of clinician-reported outcomes and photographs as primary endpoints of late normal tissue effects in breast radiotherapy trials? Results from the IMPORT LOW trial. Radiother Oncol. 2019;134:220-30.

27. Meattini I, et al. Accelerated partial breast irradiation using intensity modulated radiotherapy versus whole breast irradiation: Health-related quality of life final analysis from the Florence phase 3 trial. Eur $J$ Cancer. 2017;76:17-26.

28. Livi L, et al. Accelerated partial breast irradiation using intensity-modulated radiotherapy versus whole breast irradiation: 5-year survival analysis of a phase 3 randomised controlled trial. Eur J Cancer. 2015;51(4):451-63.

29. Vaidya JS, et al. Risk-adapted targeted intraoperative radiotherapy versus whole-breast radiotherapy for breast cancer: 5-year results for local control and overall survival from the TARGIT-A randomised trial. The Lancet. 2014;383(9917):603-13.

30. Vaidya JS, et al. Targeted intraoperative radiotherapy versus whole breast radiotherapy for breast cancer (TARGIT-A trial): an international, prospective, randomised, non-inferiority phase 3 trial. Lancet. 2010;376(9735):91-102.

31. Polgár $C$, et al. Breast-conserving therapy with partial or whole breast irradiation: Ten-year results of the Budapest randomized trial. Radiother Oncol. 2013;108(2):197-202.

32. Veronesi $U$, et al. Intraoperative radiotherapy versus external radiotherapy for early breast cancer (ELIOT): a randomised controlled equivalence trial. Lancet Oncol. 2013;14(13):1269-77.

33. Rodriguez N, et al. Five-year outcomes, cosmesis, and toxicity with 3-dimensional conformal external beam radiation therapy to deliver accelerated partial breast irradiation. Int J Radiat Oncol Biol Phys. 2013;87(5):1051-7.

34. Poortmans P. Evidence based radiation oncology: breast cancer. Radiother Oncol. 2007;84(1):84-101.
35. Fisher B, et al. Twenty-year follow-up of a randomized trial comparing total mastectomy, lumpectomy, and lumpectomy plus irradiation for the treatment of invasive breast cancer. N Engl J Med. 2002;347(16):1233-41.

36. Boyages J, et al. Early breast cancer: predictors of breast recurrence for patients treated with conservative surgery and radiation therapy. Radiother Oncol. 1990;19(1):29-41.

37. Liljegren $\mathrm{G}$, et al. Sector resection with or without postoperative radiotherapy for stage I breast cancer: five-year results of a randomized trial. Uppsala-Orebro Breast Cancer Study Group. J Natl Cancer Inst. 1994;86(9):717-22.

38. Forster $\mathrm{T}$, et al. Accelerated partial breast irradiation: a new standard of care? Breast Care. 2020;15(2):136-47.

39. Dutta SW, et al. Intraoperative radiation therapy for breast cancer patients: current perspectives. Breast Cancer (Dove Med Press). 2017;9:257-63.

40. Bennion NR, et al. Accelerated partial breast radiotherapy: a review of the literature and future directions. Gland Surg. 2018;7(6):596-610.

41. Qi XS, White J, Li XA. Is alpha/beta for breast cancer really low? Radiother Oncol. 2011;100(2):282-8.

42. Niska JR, et al. Choosing wisely after publication of level I evidence in breast cancer radiotherapy. Breast Cancer (Dove Med Press). 2018;10:31-7.

43. Hepel JT, et al. American Brachytherapy Society consensus report for accelerated partial breast irradiation using interstitial multicatheter brachytherapy. Brachytherapy. 2017;16(5):919-28.

44. Polgar C, et al. Patient selection for accelerated partial-breast irradiation (APBI) after breast-conserving surgery: recommendations of the Groupe Europeen de Curietherapie-European Society for Therapeutic Radiology and Oncology (GEC-ESTRO) breast cancer working group based on clinical evidence (2009). Radiother Oncol. 2010;94(3):264-73.

45. Korzets $Y$, et al. Toxicity and clinical outcomes of partial breast irradiation compared to whole breast irradiation for early-stage breast cancer: a systematic review and meta-analysis. Breast Cancer Res Treat. 2019;175(3):531-45.

46. Corica T, et al. Cosmesis and breast-related quality of life outcomes after intraoperative radiation therapy for early breast cancer: a substudy of the TARGIT-A trial. Int J Radiat Oncol Biol Phys. 2016;96(1):55-64.

47. Corica T, et al. Cosmetic outcome as rated by patients, doctors, nurses and BCCT.core software assessed over 5 years in a subset of patients in the TARGIT-A Trial. Radiat Oncol. 2018;13(1):68.

\section{Publisher's Note}

Springer Nature remains neutral with regard to jurisdictional claims in published maps and institutional affiliations.
Ready to submit your research? Choose BMC and benefit from:

- fast, convenient online submission

- thorough peer review by experienced researchers in your field

- rapid publication on acceptance

- support for research data, including large and complex data types

- gold Open Access which fosters wider collaboration and increased citations

- maximum visibility for your research: over $100 \mathrm{M}$ website views per year

At BMC, research is always in progress.

Learn more biomedcentral.com/submissions 